\title{
Childhood obesity and parental weight perceptions: an update
}

\begin{abstract}
Recent data continue to reveal the persistence of high rates of childhood obesity in many regions of the world. This brief describes the most recent research on this topicfrom the perspective of the role played by parental weight perceptions, a variable that has been linked to the persistence of and apparent burgeoning of childhood obesity/ overweight prevalence rates, regardless of country of origin. To update the literature on this topic, English language peer-reviewed publications from 2016-2017 on the topics of overweight, obesity and parental health literacy were specifically reviewed. Findings from the available studies reveal many inaccurate parental perceptions have been observed among children at risk for childhood obesity, an ongoing widespread health concern. This epidemic also appears to be influenced by the accuracy of the perceptions of parents regarding their child's weight status. It is concluded that strategies to help parents detect and intervene upon any prevailing overweight risk for this oftentimes irreversible health condition are strongly indicated.
\end{abstract}

Keywords: childhood obesity, overweight, parental perceptions, prevention
Volume 7 Issue 4 - 2017

\section{Ray Marks}

School of Health \& Professional Studies, City University of New York, USA

\author{
Correspondence: Ray Marks, York College, and Department \\ of Health and Behavior Studies, Teachers College, Columbia \\ University, New York, NY, USA, \\ Email rmarks@york.cuny.edu,rm226@columbia.edu
}

Received: November 08, 2017 | Published: November 17, 2017

\section{Introduction}

\section{Childhood overweight and parental perceptions}

Childhood overweight remains an unrelenting public health challenge that shows few signs of abating, ${ }^{1-4}$ despite considerable efforts to identify risk factors for this condition and to carry out suitable related strategies. As outlined in some recent research, ${ }^{5}$ parents, who have great influence over the child's well-being may be implicated in this regard. ${ }^{6}$ In particular, parents who repeatedly misperceive either the importance of childhood overweight or the presence of childhood overweight or both may place their children at risk for early onset of overweight. This potentially modifiable factor may hence be a highly important element to consider in efforts to ameliorate childhood obesity, especially among groups with low health literacy.

\section{Aims}

This brief provides an updated examination of whether erroneous parental perceptions continue to play a possible role in mediating overweight problems in children even though this situation has been documented for some time. ${ }^{7-9}$ Sought were recent data that examined the degree to which parents continue to commonly misperceive their children's actual body weight status, and the possible ramifications of these observations. All types of research were deemed acceptable and the results of the search strategy used when applying the key terms childhood obesity and parental weight perceptions is shown below.

\section{Findings}

Tables 1 \& 2 .

Table I Number of resources available on topic 2015-2017

\begin{tabular}{lll}
\hline Data base & $\begin{array}{l}\text { Number of } \\
\text { references }\end{array}$ & $\begin{array}{l}\text { Number of appropriate } \\
\text { references }\end{array}$ \\
\hline $\begin{array}{l}\text { Academic Search } \\
\text { Complete }\end{array}$ & 5 & I \\
Cinahl & 3 & 1 \\
PUBMED & 122 & 25 \\
Scopus & 65 & 6 \\
*Web of Science & 122 & 30 \\
\hline
\end{tabular}

*Most useful data base

Table 2 Selected key publications on topic of childhood obesity and parental perceptions published in 2016 and 2017

\section{\begin{tabular}{l}
$\begin{array}{l}\text { Reference Key findings } \\
\text { source }\end{array}$ \\
\hline
\end{tabular}}

Al-Mahaimeed Parents with overweight/obese children had significantly more misclassifications than those with normal weight children. $90 \%$ parents et al. 10 of the $8 \mathrm{I}$ overweight children misclassified and reported their child had a normal weight, while $65 \%$ of parents of the $6 \mathrm{I}$ obese children, et al. ${ }^{10} \quad$ misclassified the child's weight status.

Almoosawi of 'normal' weight or 'overweight' when they were actually 'overweight' or 'obese', respectively.

et al." Children whose parents did not correctly perceive their weight status scored lower on the 'healthy' dietary pattern measure.

Avila-Ortiz that will disappear over time.

et al. ${ }^{12}$ The weight of the majority of the obese boys in the sample was underestimated. 
Table Continued...

\begin{tabular}{ll}
$\begin{array}{l}\text { Reference } \\
\text { source }\end{array} \quad$ Key findings \\
\hline
\end{tabular}

Brown et al. ${ }^{13}$

Among low income adults, parents of overweight infants infrequently recognized their infants were overweight.

At 12 months, overweight mothers were significantly more likely to underestimate their child's weight status $(p=.008)$.

Ashraf et al. ${ }^{14} \quad 58 \%$ of mothers and fathers of 330 children incorrectly perceived their child's weight status.

Chang et al. ${ }^{15}$

Parent under-perception of weight was common but more likely in boys than girls $(\chi=4.9 \mathrm{I}, \mathrm{p}=0.03)$.

Parent under-perception of child weight and pressure to eat were more common in boys.

Cheng et al. ${ }^{16}$ Singaporean mothers of overweight children may not perceive their child's weight accurately.

Cullinan et Among non-obese parents, those who are better-educated report their child's weight status more accurately, but among obese parents, overweight/obesity.

Gauthier et Approximately half of 83 parents of 2-5year old children underestimated their child's weight status; especially overweight/obese parents.

Over one-third of 55 mothers misperceived their child's weight status [9\% $(n=5)$ overestimated; $27 \%(n=15)$ underestimated].

Hernandez Mothers of sons were less accurate compared with mothers of daughters. For every one unit increase in maternal BMI, mothers had I3\% higher odds of being concerned of their child becoming overweight. Concerned mothers had $82 \%$ lower odds of underestimating their child's weight.

De Grubb et De Grubb MC et al. found that mothers were significantly more likely to underestimate their child's weight status compared to measured al. ${ }^{20}$ BMls, particularly during verbal appraisals. In no case, did parents identify their children as being "obese."

Inaccurate maternal weight perceptions occurred in $34.8 \%$ of studied cases. Mothers of high weight children were inaccurate perceptions than those of more healthy weight (OR=4.6;95\% Cl 2.0-I0.7), and mothers of children attending well-child care were less likely to have inaccurate perceptions than others $(\mathrm{OR}=0.3,95 \% \mathrm{Cl} 0.1-0.9)$.

Hong et al. $^{22}$

$41.8 \%$ of parents misperceived their child's weight.

Of this group, $82 \%$ underestimated their child's weight status, regarding overweight or obesity.

The majority of mothers with children at unhealthy weights misclassified and normalized their child's weight status.

McDonald et al. ${ }^{23}$

McKee et al. ${ }^{24}$

Miller et al. ${ }^{25}$

Murphy et al. ${ }^{26}$

Pasch et al. ${ }^{27}$

Ramiro

Gonzalez $^{28}$

Warkenton

et al. ${ }^{29}$

These mothers did not recall a health professional raising concerns regarding their child's weight.

Highest misclassification rates occurred for overweight children.

2/5 parents misperceived their child's weight status; parents who misperceived their child's weight were I2times more likely to have a child who was obese.

Parents who perceived heavier weight as healthier or misperceived their own child's weight were more likely to have a child with obesity. This latter association held regardless of ethnicity.

Parental perception of weight status was impaired among parents of overweight children regardless of gestational age.

Although $50 \%$ of children were overweight/obese, only II\% of mothers and $10 \%$ of fathers perceived their children as being somewhat or very overweight. Multiple regressions controlling for covariates (parental BMI and child age) showed that parents who preferred a heavier child body size underestimated their children's weight more, compared to those who preferred a leaner child $(\beta$ for mothers=.I3, $p<.03 ; \beta$ for fathers $=.17, p<.03)$.

Parental misperception of childhood excess weight increased from $60.8 \%$ to $71.4 \%$ ( $\mathrm{p}<.00$ I). From 20 II-20I 2 despite reduced consumption of soft drinks and snacks, and there was low adherence to dietary recommendations, hours of sleep were inadequate, and sedentary habits prevailed.

Overall, $48.05 \%$ of parents studied incorrectly classified their child's

weight; with $45.08 \%$ underestimating, and $3 \%$ overestimating this. Children with higher body mass indices $(O R=2.03 ; p<0.00 \mathrm{I})$ and boys $(O R=1.70 ; p<0.00 I)$ were more likely to have their weight status underestimated by parents.

\section{Discussion}

Research on childhood overweight and obesity continues to support the view that this health condition remains widespread across most of the developed world, and undeveloped world. Impacting this problem is the fact gleaned from a considerable body of research that childhood obesity prevails at high rates because the presence of adiposity often goes undetected. ${ }^{9-30}$ Indeed, a fairly substantive volume of research articles on this topic demonstrates that parental child weight perceptions are often erroneous, and even when they are accurate, parents subsequent behaviors can contribute inadvertently to the onset or persistence of childhood and adult obesity states.

Consequently, preventive programs that include efforts to increase the mother's or caregiver's weight status perception ${ }^{31}$ are strongly indicated. In particular, paediatricians need to be aware of this issue, as well as able to carefully convey the reasons why parents should be vigilant in this respect, as well as what constitutes childhood 
overweight in order to avert the many adverse possible health consequences of these erroneous perceptions. ${ }^{32}$ Taking the parents culture into account, and providing them with practical tools to aid in the interpretation of their child's body size, as well as effective guidelines on how to help their children maintain, achieve, or attain their ideal weight status is likely to be very helpful as well.

This process is not a simplest one, however, because one piece of earlier research clearly showed that parents with inaccurate perceptions of their child's weight status are likely to ignore appropriate health messages even in the event these are indicated as discussed by Aljunaibi et al. ${ }^{9}$ Research also shows that errors in maternal parental understandings are not uniform, and vary according to gender, ${ }^{32}$ so universal recommendations are unlikely to be optimally successful, especially if the mother is young and has a daughter, rather than a son. ${ }^{31}$ Even if clinicians attempt to solve this issue, caution as to how this is done is advised given that Jones ${ }^{33}$ found parents who misidentified their children's weight status, did not understand, use or trust clinical measures, thus often remaining detached from the issue.

New research further shows that there is a fine line in how a parent processes information and behaves if they perceive a child is overweight, as this perception is not always followed by attempts to reduce the problem, but is clearly predictive of obesity in later life. Hernandez et al., ${ }^{19}$ too recently found that even though mothers with higher body mass indices tended to be more concerned than those of normal weight about their child becoming overweight, concerned mothers had $82 \%$ lower odds of underestimating their child's weight. Other research by Hong et al., ${ }^{35}$ shows that both parents and health professionals demonstrate low sensitivity in identifying children's weight status, so both may require a degree of appropriate education. Min et al., ${ }^{34}$ showed as well that in China, mothers who perceive their child as overweight are more likely to encourage their child to exercise and modify their diet for weight management, but this encouragement does not seem to improve the child's health behaviors and weight status.

However, as reiterated by Chaperro, ${ }^{35}$ the larger problem is that if parents fail to recognize their child is indeed overweight, they may be less inclined to recognize the importance of applying targeted obesity programs to their family. Wen \& $\mathrm{Hui}^{36}$ concluded that the accurate classification of children's weights by parents could help reduce the prevalence of childhood obesity, but clearly genetic dispositions, socioeconomic status, social norms and other factors are possible barriers to successful prevention in this sphere that need to be understood and overcome if possible. Moreover, even if parents identify their child is overweight, parents may not be able to help their children without the support of school-based childhood obesity prevention and intervention programs to reinforce the important role of parental mediation of their child's weight status, if this is on the excessive side. McDonald et al., ${ }^{23}$ noted mothers who displayed erroneous perceptions of their child's excess weight status often failed to recall their pediatrician or provider had discussed this issue with them. Moreover, Hong et al., ${ }^{22}$ found that parents of overweight children often took no action because they felt this was a 'temporary' state.

To assist in addressing all these overlapping issues, and to arrive at a more desirable outcome than is presently observed, careful needs assessments, followed by insightful culturally appropriate and targeted strategies, that include partnerships between parents, clinicians, dieticians, health educators, and school nurses are clearly indicated. However, according to Hernandez et al., ${ }^{19}$ the key issue is that parents must be able to accurately perceive their child's weight status in the first place. In this regard, Hong et al., ${ }^{37}$ suggest that family-based weight control interventions that incorporate education concerning the importance of overcoming parental misperceptions of the body weight may be helpful, while Hong et al., ${ }^{22}$ suggest health professionals use the Centers for Disease Control and Prevention categories to facilitate parents' ability to accurately identify overweight or 'at risk' children. In any event, early assessments of a parent's perceptions of their child's weight, followed by regular follow up sessions, appropriate feedback, continuing education efforts, and efforts to chart the child's weight status over time, are likely to prove more helpful than not. ${ }^{38,39}$ Highlighting this issue and its solutions in vulnerable communities, maternal health clinics, pediatrician offices and pre-school settings will likely be very helpful as well.

Clearly, the earlier parents are apprised of the importance of not under estimating their child's weight and are provided with supportive strategies to avoid this, the better the outlook for resolving the childhood obesity epidemic because regardless of culture and age, Reyes and Higgins ${ }^{39}$ found that the younger the child is, the more likely it is that the parent will underestimate their weight status. To intervene on this problem, they suggest clinicians engage in early discussions that focus on what a healthy weight is and how having a healthy weight can predict future health. Moreover, in addition to addressing and recognizing early concerns and assessing the accuracy of parental weight perceptions, delivering these strategies successively over extended periods of time is likely to prove especially successful. In this regard, Edwards et al., ${ }^{40}$ found the Fitwits TM intervention with interactive flashcards and before and- after surveys to significantly improve the accuracy of parents' perceptions of their children's body mass status.

Hochdorn et al., ${ }^{41}$ who reviewed 37 papers that focused on research conducted in different geopolitical contexts, similarly concluded that adequate educational support for promoting parents' awareness and their realistic recognition of their children's weight should be implemented in all healthcare policies addressing childhood obesity. Duarte et al., ${ }^{21}$ further suggested attendance at well-child visits may be an effective way to decrease inaccuracies in maternal child weight judgments, and again reinforced the importance of incorporating the influence of salient health professionals from the earliest point in time in childhood obesity prevention. Duncan et al., ${ }^{42}$ who found a declining tendency among parents to perceive overweight children appropriately in a 2015 study, recommended strategies be put in place to explore how to encourage clinician discussions with parents about appropriate weight for their child as well as strengthen their capacity for childhood obesity prevention.

In sum- although many parents fail to recognize their child is overweight as discussed by Lundahl et al., ${ }^{43}$ parents who recognize their children as being at risk for overweight have a better chance of helping them to develop life affirming skills, and behaviors, skills for making effective judgments and choices, as well as offering supportive and stress free environments that make the healthier choice the easier choice.

Unfortunately, research continues to show parents commonly underestimate the weight status of overweight or obese children, regardless of country of origin, as outlined by Regber et al., ${ }^{41}$ in a study of eight countries in Europe ${ }^{44}$ and Musaad et al., ${ }^{45}$ in an American based study where $93 \%$ of youth were not correctly perceived as overweight or obese by the parent. Another issue is that accurate parental perceptions of child weight may counter 
intuitively contribute to obesity. ${ }^{30}$ Another finding warranting careful thought is that parents who prefer a heavier child body size appear to underestimate their child's weight to a greater degree than parents who prefer a leaner child, and thus attempts by pediatricians to correct parents' misperceptions if not carefully construed may damage interpersonal rapport and ultimately lead to failure. ${ }^{27}$ Parkinson et al., ${ }^{46}$ found mothers tended to classify their child as overweight in only more extreme cases. However, no beneficial impact was shown on later child body mass in overweight children even when mothers classified their child's weight status as overweight at an earlier stage, suggesting education alone is insufficient for reducing the risk of later adverse health events, nor protective against further weight gain as outlined by Robinson. ${ }^{30}$

\section{Conclusion}

Current research findings outlined in Table 2 as well as past research support the view that inaccurate parental estimates of the extent of their child's overweight, when present, potentially continues to play an important role in influencing childhood and adult obesity rates. ${ }^{20}$ Although Robinson ${ }^{47}$ found that perceiving a child is 'fat', still tends to correlate with their future weight, Etelson et al., ${ }^{48}$ suggested pediatricians should provide weight loss advice to parents, and focus on both the assessment of the parent's perceptions, as well as their understandings of this problem. Warkentin et al., ${ }^{29}$ propose that since awareness of weight problems is essential for prevention and treatment, clinical practitioners can help parents at high risk of misperception to correctly evaluate their child's weight status. However, Pasch et al. ${ }^{27}$ caution that attempts by pediatricians to correct parents' misperceptions about child weight may damage rapport and ultimately fail if the misperception is actually a reflection of parents' preferences, which may not be readily amenable to change. They suggest research in the future should hence address optimal methods of communication about child overweight which take into account parent preferences. Garrett-Wright ${ }^{49}$ who studied perceptions of parents among preschoolers in the context of obesity, indicated that assessing parental perceptions of preschool children's body weight could help providers to better comprehend how parents view their children and could thus lead to more efficient suitably tailored educational interventions in the future.

Approaches that might be tested in future work include some of the above mentioned ideas, plus efforts to educate parents about how they can help to counteract the unhealthy influence of television on diet, and physical activity ${ }^{50}$ if they deem the child is on the 'overweight' side. Basic research that examines the correlates examined in this brief, and the importance of providing parents with cogent evaluative skills and follow up strategies should also be examined.

In the interim we strongly concur with Adjunaibi et al., ${ }^{9}$ and Warshburger et al., ${ }^{51}$ that erroneous parental body weight perceptions and absence of related risk reduction efforts reduce opportunities to prevent childhood and adult obesity. Along with further research to enhance understanding of this issue and its solutions, ${ }^{52}$ continuous feedback on the health risks associated with childhood overweight may increase maternal readiness for change in the interim and appears highly desirable until better options are forthcoming. ${ }^{51}$

\section{Acknowledgements}

None.

\section{Conflict of interest}

The author declares no conflict of interest.

\section{References}

1. Foster B, Maness T, Aquino C. Trends and disparities in the prevalence of childhood obesity in South Texas between 2009 and 2015. J Obesity. 2017;2017:1424968.

2. Farrag NS, Cheskin LJ, Farag MK. A systematic review of childhood obesity in the Middle East and North Africa (MENA) region:health impact and management. Adv Pediatr Res. 2017;4:6.

3. Zhang YX, Wang SR, Li SY. Prevalence of severe obesity and its association with elevated blood pressure among children and adolescents in Shandong, China. Blood Press Monit. 2017;22(6):345-350.

4. Martinson ML, Chang YL, Han WJ, et al. Child overweight and obesity in Shanghai, China: contextualizing Chinese socioeconomic and gender differences. Int J Behav Med. 2018;25(1):141-149.

5. Tompkins CL, Seablom M, Brock DW. Parental perception of child's body weight: a systematic review. J Child and Fam Studies. 2015;24(5):1384-1391.

6. Melis Yavuz H, Selcuk B. Predictors of obesity and overweight in preschoolers: the role of parenting styles and feeding practices. Appetite. 2017;120:491-499.

7. Manios Y, Moschonis G, Karatzi K, et al. Large proportions of overweight and obese children, as well as their parents, underestimate children's weight status across Europe. The ENERGY (European Energy Balance Research to Prevent Excessive Weight Gain among Youth) project. Public Health Nutr. 2015;18(12):2183-2190.

8. Chen HY, Lemon SC, Pagoto SL, et al. Personal and parental weight misperception and self-reported attempted weight loss in US children and adolescents, National Health and Nutrition Examination Survey, 2007-2008 and 2009-2010. Prev Chronic Dis. 2014;11:132E.

9. Aljunaibi A, Abdulle A, Nagelkerke N. Parental weight perceptions: a cause for concern in the prevention and management of childhood obesity in the United Arab Emirates. PLoS One. 2013;8(3):e59923.

10. Al-Mohaimeed AA. Parents' perception of children's obesity, in AlQassim, Saudi Arabia. J Family Community Med. 2016;23:179-183.

11. Almoosawi S, Jones AR, Parkinson KN, et al. Parental perception of weight status: influence on children's diet in the Gateshead Millennium Study. PLoS One. 2016;11(2):e0144931.

12. Ávila-Ortiz MN, Castro-Sánchez AE, Zambrano-Moreno A. Mexican mothers' perceptions of their child's body weight. Health Soc Care Community. 2017;25:569-577.

13. Brown CL, Skinner AC, Yin HS, et al. Parental perceptions of weight during the first year of life. Acad Pediatr. 2016;16(6):558-564.

14. Ashraf H, Shamsi NI, Ashraf R. Parental perception and childhood obesity: contributors to incorrect perception. J Pak Med Assoc. 2017;67(2):214-219.

15. Chang L, Mendelsohn A, Fierman A, et al. Perception of child weight and feeding styles in parents of Chinese-American preschoolers. $J$ Immigrant \& Minority Health. 2017;19(2):302-308.

16. Cheng TS, Loy SL, Cheung YB, et al. Singaporean mothers' perception of their three-year-old child's weight status: a cross-sectional study. PLoS One. 2016;11(1):e0147563.

17. Cullinan J, Cawley J. Parental misclassification of child overweight/ obese status: the role of parental education and parental weight status. Econ Hum Biol. 2017;24:92-103.

18. Gauthier KI, Gance-Cleveland B. Hispanic parental perceptions of child weight in preschool-aged children: an integrated review. Child Obes. 2015;11(5):549-559.

19. Hernandez DC, Reesor L, Kabiri LS. Maternal concerns and perceptions of elementary school-age children's weight status. J Spec Pediatr Nurs. 2017:22(4). 
20. de Grubb MC, Salemi JL, Kihlberg C, et al. Disparities in accuracy of maternal perceptions of obesity among Hispanic Children. J Health Care Poor Underserved. 2017;28(3):1208-1221.

21. Duarte LS, Fujimori E, Minagawa Toriyama AT, et al. Brazilian maternal weight perception and satisfaction with toddler body size:a study in primary health care. J Pediatr Nurs. 2016;31(5):490-497.

22. Hong I, Dodds CB, Coker-Bolt P, et al. How accurately do both parents and health professionals assess overweight in children? Pediatr Phys Ther. 2017;29:283-285.

23. McDonald SW, Ginez HK, Vinturache AE, et al. Maternal perceptions of underweight and overweight for 6-8 years olds from a Canadian cohort:reporting weights, concerns and conversations with healthcare providers. BMJ Open. 2016;6(10):e012094.

24. McKee C, Long L, Southward LH, et al. The role of parental misperception of child's body weight in childhood obesity. $J$ Pediatr Nurs. 2016;31(2):196-203.

25. Miller D, Johnson W, Miller M, et al. Caregiver perceptions of childhood weight: demographic moderators and correlates. Child Care Health Dev. 2016;42(3):370-374.

26. Murphy LT, Skinner AC, Check J, et al. Parental perceptions of weight status in preterm compared with term infants. Am J Perinatol. 2016;33(14):1371-1376.

27. Pasch LA, Penilla C, Tschann JM, et al. Preferred child body size and parental underestimation of child weight in Mexican-American families. Matern Child Health J. 2016;20(9):1842-1848.

28. Ramiro-González MD, Sanz-Barbero B, Royo-Bordonada MÁ. Childhood excess weight in spain from 2006 to 2012. determinants and parental misperception. Rev Esp Cardiol (Engl Ed). 2017;70:656-663.

29. Warkentin S, Mais LA, Latorre MDRDO, et al. Factors associated with parental underestimation of child's weight status. J Pediatr (Rio J). 2017;7557(16):30300.

30. Robinson E. Overweight but unseen: a review of the underestimation of weight status and a visual normalization theory. Obes Rev. 2017;18(10):1200-1209.

31. Souto-Gallardo MC, Jiménez-Cruz A, Bacardí-Gascón M. Parents perception of weight status of Mexican preschool children using different tools. Arch Latinoam Nutr. 2011;61(4):382-388.

32. Camargo AP, Barros Filho Ade A, Antonio MÂ, et al. The non perception of obesity can be an obstacle to the role of mothers in taking care of their children. Cien Saude Colet. 2013;18(2):323-333.

33. Jones AR, Parkinson KN, Drewett RF, et al. Parental perceptions of weight status in children: the Gateshead Millennium Study. Int J Obes (Lond). 2011;35(7):953-962.

34. Min J, Wang VH, Xue H, et al. Maternal perception of child overweight status and its association with weight-related parenting practices, their children's health behaviours and weight change in China. Public Health Nutr. 2017;20(12):2096-2103.

35. Chaparro MP, Langellier BA, Kim LP, et al. Predictors of accurate maternal perception of their preschool child's weight status among Hispanic WIC participants. Obesity. 2011;19(10):2026-2030.
36. Wen X, Hui SS. Chinese parents' perceptions of their children's weights and their relationship to parenting behaviours. Child Care Health Dev. 2011;37(3):343-351.

37. Hong SA, Peltzer K, Jalayondeja C. Parental misperception of child's weight and related factors within family norms. Eat Weight Disord. 2017;519:017-0399-4

38. Rachmi CN, Hunter CL, Li M, et al. Perceptions of overweight by primary carer (mothers/grandmothers) of under five and elementary school-aged children in Bandung, Indonesia: a qualitative study. Int $J$ Behav Nutr Phys Act. 2017;14:101.

39. Reyes I, Higgins M. Parental perception of child's body mass index and health within primary care. J Am Assoc Nurse Pract. 2017;29(7):375383.

40. Edwards BA, Powell JR, McGaffey A, et al. Fitwits(TM) Leads to improved parental recognition of childhood obesity and plans to encourage change. J Am Board Fam Med. 2017;30(2):178-188.

41. Hochdorn A, Faleiros VP, Camargo BV, et al. Obese children are thin in parents' eyes: a psychologically, socially, or culturally driven bias? $J$ Health Psychol. 2016;1:1359105316676328.

42. Duncan DT, Hansen AR, Wang W, et al. Change in misperception of child's body weight among parents of American preschool children. Child Obes. 2015;11(4):384-393.

43. Lundahl A, Kidwell KM, Nelson TD. Parental underestimates of child weight: a meta-analysis. Pediatrics. 2014;133:e689-703.

44. Regber S, Novak M, Eiben G, et al. Parental perceptions of and concerns about child's body weight in eight European countries - the IDEFICS study. Pediatr Obes. 2013;8:118-129.

45. Musaad SM, Paige KN, Teran-Garcia M, et al. The Strong Kids Research Team. Childhood overweight/obesity and pediatric asthma: the role of parental perception of child weight status. Nutrients. 2013;5(9):37133729.

46. Parkinson KN, Reilly JJ, Basterfield L, et al. Mothers' perceptions of child weight status and the subsequent weight gain of their children: a population-based longitudinal study. Int J Obes. 2017;41(5):801-806.

47. Robinson E, Sutin AR. Parental perception of weight status and weight gain across childhood. Pediatrics. 2016;137(5):e20153957.

48. Etelson D, Brand DA, Patrick PA, et al. Childhood obesity: do parents recognize this health risk? Obes Res. 2003;11(11):1362-1368.

49. Garrett-Wright D. Parental perception of preschool child body weight. $J$ Pediatr Nurs. 2011;26(5):435-445.

50. Harris JL, Bargh JA. Television viewing and unhealthy diet: implications for children and media interventions. Health Commun. 2009;24(7):660673

51. Lydecker JA, Grilo CM. The apple of their eye: attitudinal and behavioral correlates of parents' perceptions of child obesity. Obesity. 2016;24:1124-1131.

52. Warschburger P, Kröller K. Childhood overweight and obesity: maternal perceptions of the time for engaging in child weight management. BMC Public Health. 2012;12:295-302. 